\title{
Review
}

\section{Killers creating new life: caspases drive apoptosis- induced proliferation in tissue repair and disease}

\author{
Caitlin E Fogarty ${ }^{1}$ and Andreas Bergmann ${ }^{*, 1}$
}

Apoptosis is a carefully orchestrated and tightly controlled form of cell death, conserved across metazoans. As the executioners of apoptotic cell death, cysteine-dependent aspartate-directed proteases (caspases) are critical drivers of this cellular disassembly. Early studies of genetically programmed cell death demonstrated that the selective activation of caspases induces apoptosis and the precise elimination of excess cells, thereby sculpting structures and refining tissues. However, over the past decade there has been a fundamental shift in our understanding of the roles of caspases during cell death-a shift precipitated by the revelation that apoptotic cells actively engage with their surrounding environment throughout the death process, and caspases can trigger a myriad of signals, some of which drive concurrent cell proliferation regenerating damaged structures and building up lost tissues. This caspase-driven compensatory proliferation is referred to as apoptosis-induced proliferation (AiP). Diverse mechanisms of AiP have been found across species, ranging from planaria to mammals. In this review, we summarize the current knowledge of AiP and we highlight recent advances in the field including the involvement of reactive oxygen species and macrophage-like immune cells in one form of AiP, novel regulatory mechanisms affecting caspases during AiP, and emerging clinical data demonstrating the critical importance of AiP in cancer. Cell Death and Differentiation (2017) 24, 1390-1400; doi:10.1038/cdd.2017.47; published online 31 March 2017

\section{Facts}

- Activated caspases trigger a form of compensatory proliferation, referred to as apoptosis-induced proliferation (AiP), through secretion of mitogens.

- AiP is best characterized in epithelial cells, and is critical for epithelial wound repair and regeneration across species.

- There are several context- and tissue-specific forms of AiP currently characterized.

- The initiator caspase-dependent AiP mechanism involves JNK signaling, reactive oxygen species (ROS) and recruitment of macrophage-like immune cells.

- Sustained AiP causes tissue overgrowth, and may contribute to tumor growth and treatment resistance.

\section{Open Questions}

- Why does activation of caspases in apoptosis sometimes induce AiP and other times not? Conversely, how might caspases be controlled to at times induce only AiP in the absence of cell death?

- Are cell types other than epithelial cells subject to AiP?

- What are the direct targets of caspases in AiP? Are all targets cleaved?

- How general is the involvement of AiP in tumor development?

- Does AiP contribute to other disease processes?

\section{Death-dependent proliferation}

Most, if not all, animals have some capacity to regenerate lost tissue, but there is great variability in that capacity, dependent on the species and developmental context. Some forms of regeneration depend on compensatory proliferation, a process by which the volume of damaged or lost tissue is replaced via additional mitotic divisions within the healthy neighboring tissue (Figure 1a). The first quantitative evidence for compensatory proliferation came from studies in Drosophila melanogaster. In 1977, it was demonstrated that irradiated wing precursor tissue (imaginal discs) of the developing fly larva, despite elimination of up to $60 \%$ of cells, could yield a normal sized wing with appropriate patterning due to subsequent increase in mitosis among surviving cells. ${ }^{1}$ Follow-up studies found that the increased mitosis following apoptosis could consistently and appropriately accommodate for the lost tissue, suggesting the two processes were directly linked. ${ }^{2,3}$

Several studies in 2004 supported the concept of apoptosisdependent proliferation. In planarians, caspase-like genes are activated, and apoptotic cells are present throughout the regenerative process, well beyond the original injury. ${ }^{4}$ In newts, apoptosis was found to be required for proper limb regeneration. ${ }^{5}$ Multiple studies in Drosophila found that induction of the apoptotic machinery was sufficient to promote non-autonomous proliferation in the surrounding cells, independent of completed cell death. ${ }^{6-8}$ These and follow-up studies established that the Drosophila initiator caspase Dronc was specifically responsible for driving compensatory proliferation following initiation of apoptosis. 6,9,10

Apoptosis-induced proliferation (AiP) is the designated term for the distinct subtype of compensatory proliferation specifically triggered by the apoptotic machinery. ${ }^{11} \mathrm{AiP}$ is not a single pathway, but encompasses a variety of signaling cascades by

${ }^{1}$ Department of Molecular, Cell and Cancer Biology, University of Massachusetts Medical School, 364 Plantation Street, LRB 419, Worcester, MA 01605, USA

${ }^{*}$ Corresponding author: A Bergmann, Molecular, Cell and Cancer Biology, University of Massachusetts Medical School, 364 Plantation Street, LRB 419, Worcester, MA 01605, USA. Tel: +1 508856 6023; Fax: +1 508856 1310; E-mail: Andreas.bergmann@ umassmed.edu

Received 23.1.17; revised 26.2.17; accepted 28.2.17; Edited by E Arama; published online 31.3.17 
a AiP in transient wound healing
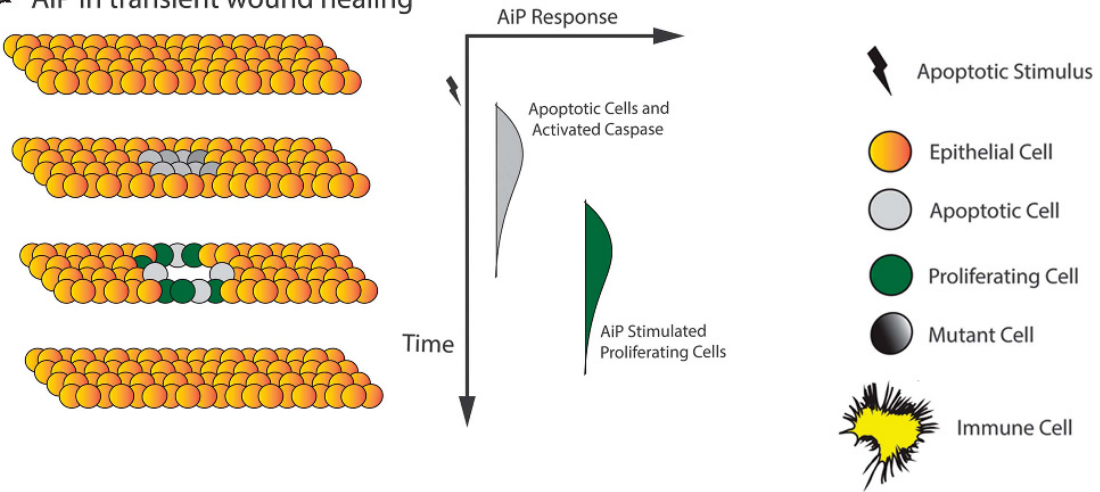

b AiP in sustained wound healing and regeneration

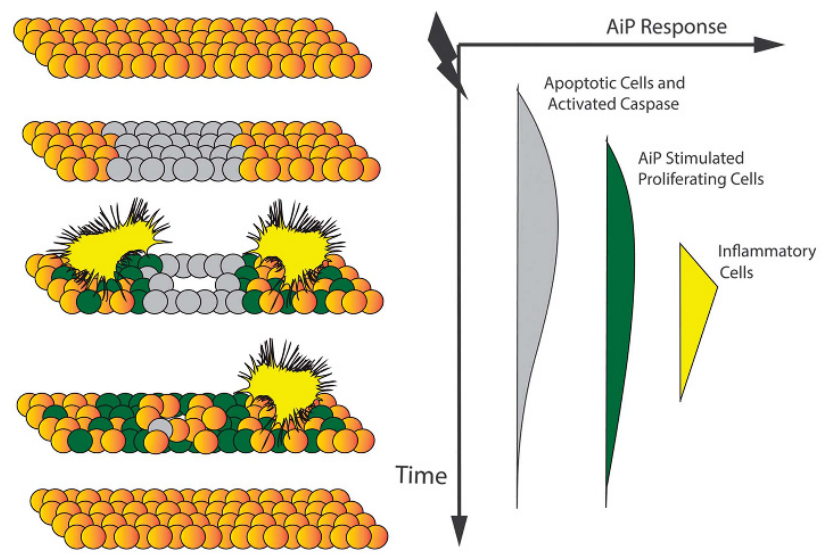

C Chronic Trauma, Inflammation, AiP, and Cancer

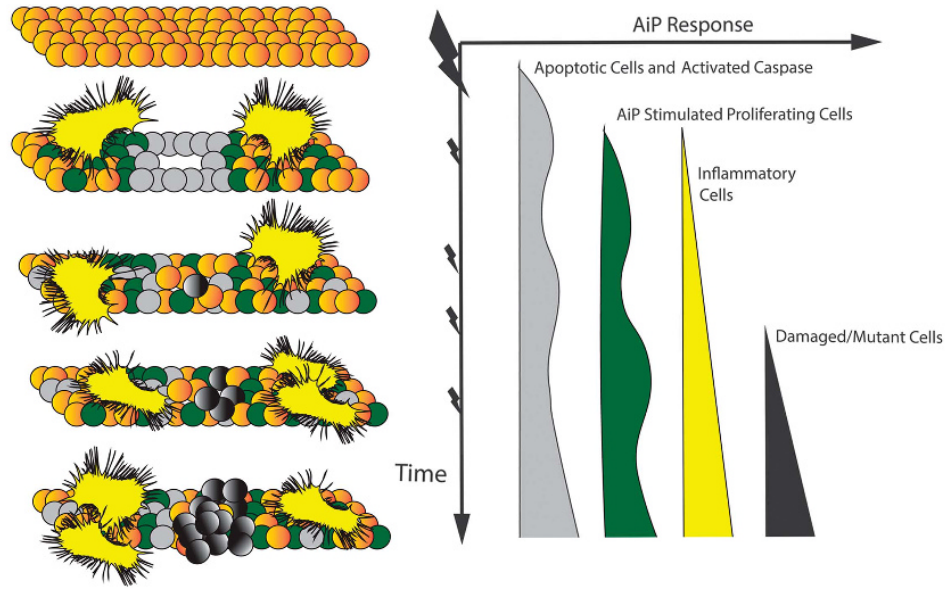

Figure 1 The Spectrum of AiP in wound healing, regeneration, and the development of cancer. On the left, shown are sheets of epithelial cells. On the right, the relative timing of caspase activity, AiP and the recruitment of immune cells as well as cancer cells (c) is illustrated. Based on the variety of caspase-dependent AiP mechanisms, it is clear that the phenomenon of AiP includes a spectrum of functions from simple transient wound healing, to more complex regeneration, to responding to chronic damage and inflammation. (a) Transient AiP is a self-limited proliferation in direct response to caspase activation in some apoptotic cells. (b) AiP associated with more significant or sustained wound healing often requires additional support including from the immune cells recruited by caspase-dependent signals such as extracellular ROS, but eventually resolves upon tissue repair. (c) Caspase-dependent AiP which occurs during ongoing or repeated damage, such as in chronic inflammatory diseases, can lead to an imbalance in cell death versus proliferation, leading to tissue dysplasia, hyperplasia, or possible neoplasia from the AiP stimulation of damaged cells containing new cancer-causing mutations

which caspases promote non-autonomous proliferation through secretion of mitogens, often in parallel to, but independent of the final execution of apoptotic cell death. $^{12-18}$ These caspase-dependent signaling path- ways play a critical role in wound healing and regeneration (Figure 1a and b). Furthermore, apoptotic caspases may also contribute to tumor initiation, caspase-dependent inflammation, and sustained AiP in tumor initiation. Tumors have been 
described as analogous to wounds that don't heal, ${ }^{19}$ and chronic inflammatory states, often characterized by repeated cycles of cell death and incomplete wound healing, are known to predispose to the development of certain cancers (Figure 1c) ${ }^{20}$ Here, we will explore the mechanisms, regulation, and significance of caspase-driven AiP.

\section{The many mechanisms of caspase-driven AiP}

The mitochondrial apoptosis pathway is well conserved among species. The major players include: (1) the death proteases-initiator and effector caspases, synthesized as inactive zymogens and activated through multimerization and proteolytic cleavage. Seven caspases in humans are involved in control of apoptosis, of which caspase-2,-8,-9 and -10 function as initiators of apoptosis, while caspase-3,-6 and -7 are the effectors of apoptosis. ${ }^{21}$ Drosophila have three caspases known to be involved in apoptosis: the initiator caspase Dronc (homolog of caspase-2,-9) and the effector caspases DrICE and Dcp-1 (homologs of caspase-3,-7). ${ }^{22}(2)$ Apaf-1/Dark, scaffolding proteins that complex with the initiator caspase (caspase-9/Dronc) to form the active apoptosome. (3) Multiple upstream pro-apoptotic and antiapoptotic factors whose opposing actions control where and when initiation of apoptosis occurs. ${ }^{22-24}$ In mammals, Bcl-2 family proteins regulate activation via the mitochondria, ${ }^{25}$ whereas in flies, the pro-apoptotic genes reaper, hid and grim activate apoptosis by antagonizing the E3-ligase Drosophila Inhibitor of Apoptosis Protein1 (DIAP1), a negative regulator of caspase activation (Figure 2a). ${ }^{26-30}$ DIAP1 monoubiquitylates the initiator caspase Dronc to inhibit its apoptotic activity. ${ }^{31-36}$ These regulatory mechanisms affect both apoptosis and caspase-driven AiP, but potentially to different degrees. $^{17,37,38}$

In mammals, to date only the effector caspase-3 and -7 have been shown to be involved in AiP. ${ }^{15,39-44}$ In Drosophila, Dronc as well as DrICE and Dcp-1 have been implicated in distinct forms of AiP. ${ }^{6,9,10,13,17,45,46}$ Here, we will discuss the roles of caspases in AiP and their effects on downstream signaling events in flies and mammals.

The Drosophila initiator caspase Dronc triggers a JNKdependent proliferative stress response. Most of the foundational work characterizing caspase-dependent proliferation has utilized genetic models of AiP in the Drosophila imaginal discs, developing epithelial tissues with high regenerative capacity. ${ }^{46,47}$ The 'undead' model, so called as pro-apoptotic genes (such as reaper or hid) are overexpressed while execution of cell death is blocked by co-expressing the effector caspase inhibitor $p 35,{ }^{48,49}$ allows for uncoupling of the functions of Dronc from the effector caspases and the actual execution of apoptosis (Figure 2b). ${ }^{6-9,17,50-52}$ This uncoupling was key to revealing the role of activated Dronc as a necessary and sufficient driver of mitogen production and AiP in developing epithelial tissues. Dronc-mediated AiP depends on activation of $\mathrm{JNK},{ }^{8,17,53}$ and the production of mitogens such as the Wnt homolog Wingless $(\mathrm{Wg})$, the EGF homolog Spitz (Spi), the interleukin-6 homolog Unpaired (Upd), and the BMP/TGF $\beta$ homolog Decapentaplegic (Dpp) (Figure 2a and b)..$^{7,8,17,51,54}$
Interestingly, heterozygosity of dronc substantially suppressed JNK-dependent AiP, but not apoptosis, 9,10,17,53,55 suggesting that there is a higher caspase threshold for activation of AiP as compared to apoptosis, when proapoptotic stimuli are present.

Initiator Caspase-Dependent AiP in Drosophila

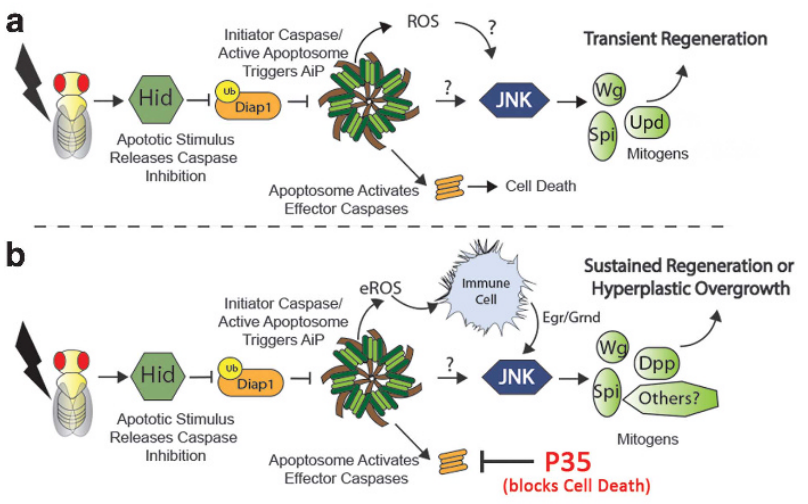

Effector Caspase-Dependent AiP Across Species

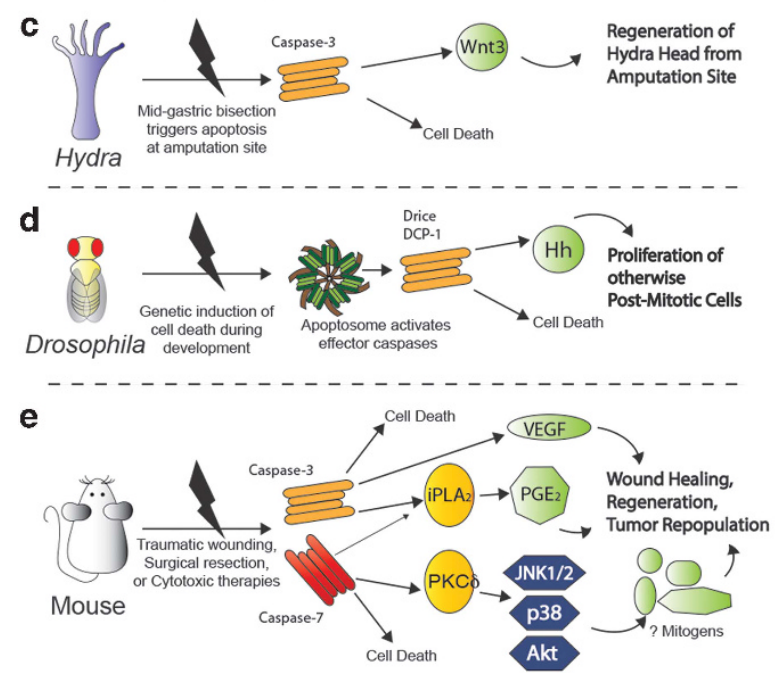

Figure 2 Mechanisms of caspase-dependent AiP. Apoptosis-induced proliferation may be induced by either initiator ( $\mathbf{a}$ and $\mathbf{b}$ ) or effector $(\mathbf{c}-\mathbf{e})$ caspases. Activation of these caspases under certain conditions results in a variety of signaling cascades, producing a variety of growth factors and other mitogenic signals. (a and $\mathbf{b}$ ) The Drosophila caspase Dronc is the only initiator caspase to date characterized as independently driving AiP. In transient regeneration (a), the active apoptosome including Dronc, triggers production of extracellular ROS and activates JNK, leading to production of the secreted mitogens Wingless $(\mathrm{Wg})$ and Spitz (Spi). More sustained regeneration $(b)$ requires additional input from recruited immune cells, signaling through the TNF homolog Eiger (Egr) and its receptor Grindelwald (Grnd), and possibly involves additional mitogens. (c-e) Effector caspases are implicated in AiP across the species, but examples shown here have confirmed the requirement of effector caspase activity. (c) In hydra, regeneration of an amputated head is dependent on caspase activity in the apoptotic cells at the regeneration site. These cells release the mitogen Wnt3. (d) The effector caspases Drice and DCP-1 are required for Hedgehog $(\mathrm{Hh})$ production in Drosophila during AiP in maturing eye tissues. (e) In mice and human cell lines, following any number of injuries, including surgical resection, radiation or cytotoxic chemotherapies, caspase-3 cleaves a phospholipase $A_{2}\left(i P L A_{2}\right)$ triggering production of prostaglandin $E_{2}\left(P G E_{2}\right)$ which stimulates AiP. Caspase-3 also is required for VEGF-A production. Caspase-7 activates the kinase $\mathrm{PKC} \delta$, activating similar stress response pathways as seen in Drosophila 
Upstream of JNK, a number of kinases and adaptor proteins contribute to the context-dependent initiation of JNK activity. ${ }^{56,57}$ Selective activation of subsets of these upstream factors directs whether JNK activity is pro-apoptotic or prosurvival. ${ }^{58}$ How activation of the same JNK (flies only have one JNK homolog) by distinct upstream factors can trigger different outcomes as diverse as death or survival remains largely enigmatic. In undead models, only dTraf2 (JNKKKK), dTAK1 (JNKKK), and both Hep and $d M K K 4$ (JNKKs) are required upstream of JNK to drive AiP. ${ }^{17}$ However, despite the identification of upstream JNK pathway components, how Dronc activates JNK during AiP was less clear-until recently.

Dronc-dependent recruitment of immune cells promotes JNK activation and enhances AiP through a positive feedback amplification loop. A prominent feature of wound healing and regeneration is the infiltration of immune cells to the site of injury, which likely contributes to efficient healing under typical conditions (Figure 1b), but they are not fundamentally required for effective regeneration. For example, mice lacking inflammatory cell lineages are still able to repair of damage to their skin. ${ }^{59,60}$ However, we have demonstrated recently that under certain circumstances caspases can signal to immune cells to contribute to sustained proliferation during AiP (Figure 2b). In epithelial tissues, Dronc activation triggers the production of extracellular reactive oxygen species (eROS) through the NADPHoxidase Duox. ${ }^{18}$ In many systems, eROS gradients are known to recruit immune cells to sites of wound healing, ${ }^{61,62}$ and in the undead model, eROS are required to recruit macrophage-like hemocytes to sites of apoptotic activity. ${ }^{18,63}$ Hemocytes in turn contribute to proliferation via amplification of JNK-dependent signaling through production of the TNF homolog Eiger (Figure 2b). ${ }^{18}$ Therefore, Dronc promotes JNK activation through an inflammatory response that involves eROS, hemocytes and TNF/Eiger signaling.

Effector caspases induce production of secreted mitogens from dying cells. Genetic screening using the undead (p35-dependent) AiP model has provided a lot of intriguing insight into the mechanisms of AiP, but excludes the contributions of effector caspases, the enzymes most directly associated with executing cell death, to AiP. Therefore, several 'genuine' or regenerative ( $p 35$-independent) models of AiP have been developed, in which tissues are first subjected to a limited pro-apoptotic stimulus, and then they are allowed to regenerate lost tissue through compensatory AiP. ${ }^{17,18,64-67}$ These genuine/regenerative models have confirmed the requirement of JNK under physiological conditions, and have been useful for investigating the spatiotemporal dynamics of AiP. ${ }^{17,18,64-66}$

The genuine/regenerative AiP models have also shown that effector caspases can promote proliferation through triggering the production of diffusible mitogens. For example, in hydra, caspase-3 activation in apoptotic cells promotes secretion of Wnt3, a key signal for proliferation and remodeling, at the site of head regeneration following mid-gastric bisection (Figure 2c). ${ }^{14}$ In apoptotic photoreceptor neurons in Drosophila, DrICE and Dcp-1 drive the upregulation and secretion of Hedgehog $(\mathrm{Hh})$ which triggers activation of the Hippo growth control pathway for AiP (Figure 2d). ${ }^{13,68}$ In mammalian tissues, caspase- 3 and -7 can cleave and activate the calcium-insensitive phospholipase $\mathrm{A}_{2}\left(\mathrm{iPLA}_{2}\right)$, which in turn produces several phospholipid signals involved in phagocyte migration, apoptotic cell detection and clearance, and prostaglandin $\mathrm{E}_{2}\left(\mathrm{PGE}_{2}\right)$, a diffusible signal that promotes stem and progenitor cell proliferation (Figure 2e). ${ }^{69-73}$ Caspase-3-dependent production of $\mathrm{PGE}_{2}$ is required for epithelial wound healing in the skin of mice, contributes to liver regeneration following partial hepatectomy, and has been implicated in tumor growth and tumor repopulation following targeted cytotoxic therapies. ${ }^{15,40}$ Caspase-7, while first linked to activation of $\mathrm{iPLA}_{2}$, seems to be more important for activation of protein kinase $\mathrm{C}$ delta $(\mathrm{PKC} \delta)$, which in turn mediates phosphorylation of Akt, p38 and JNK1/2 leading to mitogen production and tumor repopulation following radiation therapy (Figure $2 \mathrm{e}){ }^{42}$

Multiple mechanisms of AiP: redundancy or contextspecific? Controversies in the field of AiP are derived from the differences between undead and genuine/regenerative models. Depending on the model, the developmental stage, or the tissue (eye versus wing imaginal discs), different research groups conflict on the requirement and origins of specific mitogens such as Wg and Dpp. ${ }^{47,51,64,66}$ Even in our own recent work, we found that the role for hemocytes is not conserved among all forms of AiP. It is clear that Dronc triggers ROS production in response to pro-apoptotic stimuli in both undead AiP and genuine/regenerative AiP models in eye and wing discs. ${ }^{18,54}$ ROS is required for AiP in both contexts (Figure 2a and b); however, immune cell recruitment and TNF signaling does not appear to play a major role in the context of the transient regenerative period in genuine models, while it is clearly critical to the sustained proliferation in the undead model (Figure $2 a$ and b). ${ }^{18,54}$

These 'discrepancies' among the various models may in fact reflect flexibility - different mechanisms of caspase-driven AiP only activated under different contexts. There is already evidence for differences based on developmental context in flies-Dronc triggers AiP in undifferentiated eye tissue, but with a few more hours of development, the effector caspases DrICE and Dcp-1 become critical for driving AiP within the more mature differentiated tissues. ${ }^{13}$ Alternatively, 'discrepancies' could represent partial redundancy. Multiple AiP pathways may be activated sequentially or simultaneously depending on the extent and duration of the insult. Ongoing studies in Drosophila are taking advantage of the everincreasing genetic toolkit to systematically test these possibilities. At the same time, there are opportunities in other model systems to examine the conservation of these mechanisms, probing for redundancy or variability. Although the function of caspases in initiating a ROS-dependent proliferation pathway is a new addition to the field of regeneration, the downstream functions of ROS in redox signaling, damage detection, and damage response have been the focus of many recent studies. $^{74}$ Notably, the mechanisms of ROS-dependent proliferation-in recruitment of immune cells and in activating MAPK cascades-have been linked to wound healing and regeneration in Hydra, Drosophila, Xenopus and zebrafish. ${ }^{75,76}$ Hydrogen peroxide $\left(\mathrm{H}_{2} \mathrm{O}_{2}\right)$ is a diffusible ROS 
molecule, which when initially produced from the site of injury can form a chemoattractant gradient for leukocytes within the first few hours following the trauma. ${ }^{61,62}$ This transient ROS burst and the responding immune cells contribute to the temporary healing of the wound site. In contrast, sustained ROS production is required over the following $12-72 \mathrm{~h}$ for the regeneration of complete structures (e.g., amputated tails of Xenopus tadpoles). ${ }^{77,78}$ While the initial transient burst of ROS may simply be explained as nonspecific oxidative stress released from the traumatized cells, the sustained ROS are more likely actively produced by oxidases over this extended time period. The sustained ROS signal in Xenopus activates JNK and generates many of the known AiP-associated mitogens (Wnt, TGF $\beta$, BMP, etc), similar to the undead fly model. These findings, taken together with the previously reported requirement for Caspase-3 in Xenopus tail regeneration, ${ }^{12}$ highlight one of many excellent opportunities to look for conserved mechanisms of caspase-driven AiP, connecting the dots between trauma, caspases, and eROS signaling.

Intriguingly, Dronc is the only initiator caspase to date conclusively shown to drive AiP independently of effector caspases, while examples of effector caspase-driven AiP are seen from hydra to humans. It is possible that Drosophila has a uniquely evolved mechanism of Dronc-dependent AiP; however, the parallels described above would suggest further studies of caspase-2,-8 or -9-specific contributions to AiP in other systems are warranted. All future studies should be open to the possibility of multiple paths from caspases to proliferation.

\section{The regulation of caspases in AiP: a matter of life or death}

While the mechanisms downstream of caspases for some forms of AiP are better understood, essential questions about the regulation of caspases in AiP remain. AiP does not occur after every cell death. It rather appears to be confined to stress-induced apoptosis. How is this distinction regulated? In general, what distinguishes apoptotic from non-apoptotic functions of caspases? Currently, there are no definitive answers to these and related questions. However, in

Figure 3 Regulation of caspases in AiP. Caspase activation may lead to apoptotic cell death or AiP. The exact mechanisms that direct caspase activity toward death or proliferative functions are not yet clear. When considering what is known regarding one of the better characterized pathways, the Dronc-dependent AiP in Drosophila epithelium, there are several possible regulatory mechanisms which could direct Dronc toward AiP. (a) Direct biochemical modification of caspases: Non-degradative mono-ubiquitinylation of Dronc inhibits both apoptotic and AiP activity. (b) Direction of caspases by adaptors or scaffolds: other non-apoptotic functions of Dronc rely on adaptors to localize the caspase to the non-apoptotic target. It is possible that Droncmediated AiP may be facilitated by an as of yet unidentified adaptor or scaffolding protein. (c) Feedback loops allow for amplification (green arrows) or inhibition (orange lines): positive feedback from JNK upregulating the pro-apoptotic factor hid increases Dronc activity and yields a robust AiP response. Negative feedback from EGFR signaling can inhibit Hid activity, potentially dampening the AiP response. As new downstream targets are uncovered for both initiator and effector caspase-dependent AiP, we will likely develop a better understanding of how a balance among these varying positive and inhibitory signals drive caspases towards a proliferative function the following we review some recent findings on the regulation of Dronc in AiP that give a glimpse at the potential answers.

Regulating the enzyme: non-degradative mono-ubiquitylation regulates Dronc in apoptosis and AiP. It has long been known that the RING domain of DIAP1 inhibits the activity of Dronc through ubiquitylation. ${ }^{33-35}$ However, the outcome of this ubiquitylation (degradation versus nondegradative inhibition) was less clear. ${ }^{34,35,79}$ Recently, we have identified a novel regulatory mechanism by which

\section{a} Direct Modification of Caspases (Dronc)

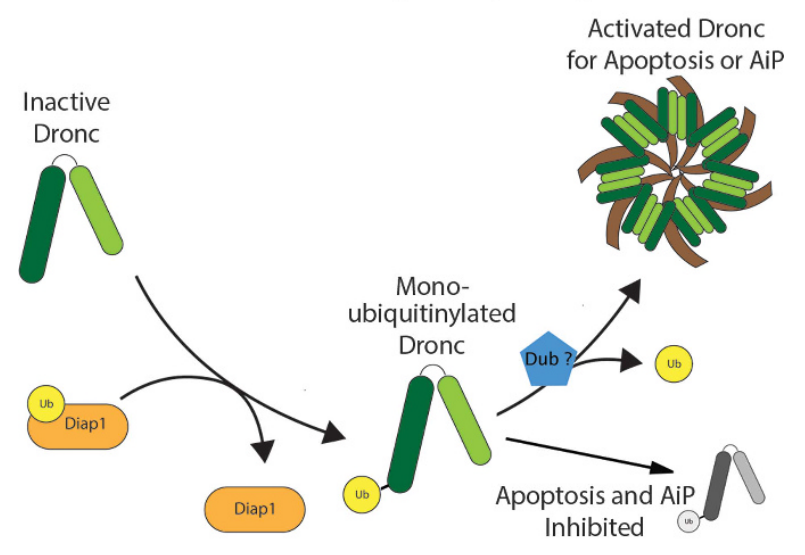

b

Possible Adaptors or Scaffolds

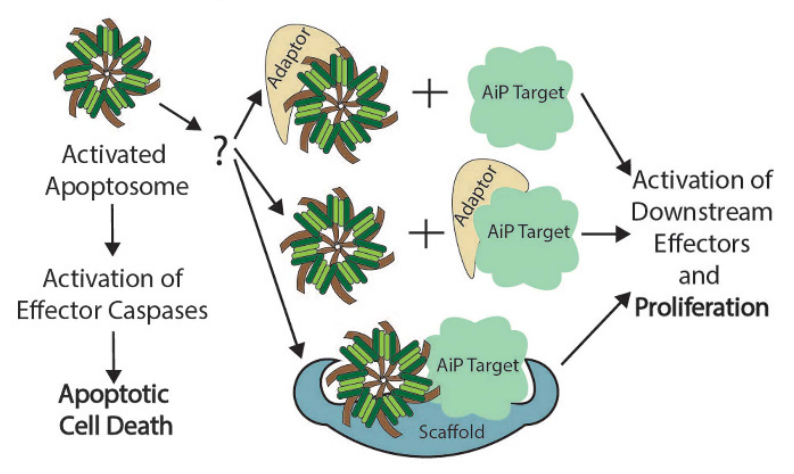

${ }^{\text {C }}$ Feedback from downstream effectors

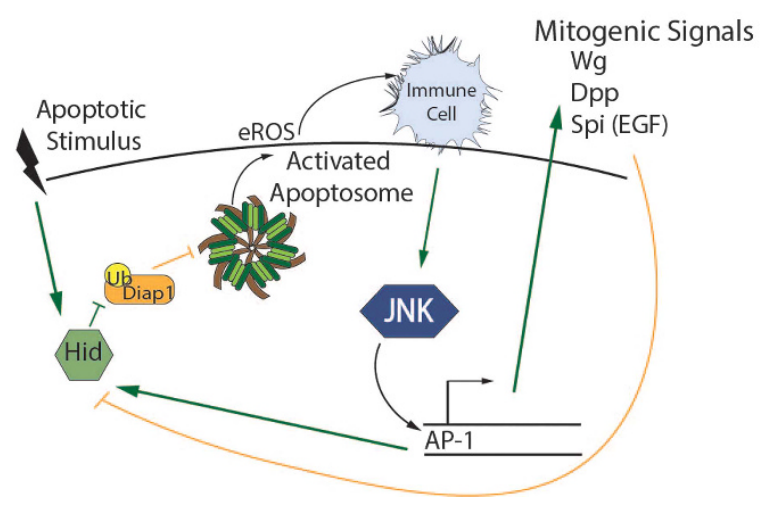


ubiquitylation controls the activity of Dronc. Dronc from embryonic, larval, pupal and adult stages is ubiquitylated only on one Lysine residue, $\mathrm{K} 78$, and this ubiquitylation is a mono-ubiquitylation which is not a mark for proteasomal degradation (Figure 3a). ${ }^{36}$ A ubiquitylation-deficient mutant of Dronc (Dronc ${ }^{\mathrm{K} 78 \mathrm{R}}$ ) interacts more efficiently with the scaffolding protein Dark and thus induces more apoptosis, suggesting that K78 mono-ubiquitylation of Dronc inhibits the interaction with Dark which explains at least partially the inhibitory role of ubiquitylation. ${ }^{36}$ Removal of K78 monoubiquitin by a deubiquitylase (DUB) may facilitate recruitment of Dronc into the Dark apoptosome (Figure 3a). While a specific DUB for this activity is not known, the recently described DUBA is a good candidate. ${ }^{80}$

Very surprisingly, a ubiquitylation-deficient and catalytically dead (due to the change of the catalytic Cys318 to Ala) double mutant of Dronc (Dronc ${ }^{\mathrm{K} 78 \mathrm{RC} 318 \mathrm{~A}}$ ) rescues the strong lethality of homozygous dronc null mutants which the catalytic-only mutant Dronc ${ }^{\mathrm{C} 318 \mathrm{~A}}$ was unable to do. ${ }^{36}$ Because expression of dronc $^{K 78 R C 318 A}$ does not rescue the inability of dronc mutants to induce apoptosis, ${ }^{36,55}$ these observations suggest that the non-apoptotic functions of Dronc are more important for the survival of the fly than its apoptotic one. Moreover, in contrast to dronc ${ }^{C 318 A}$, co-expression of dronc ${ }^{K 78 R C 318 A}$ with $p 35$ does induce $\mathrm{AiP}^{36}{ }^{36}$ suggesting that mono-ubiquitylation of Dronc serves also an inhibitory role for the ability of Dronc to induce AiP (Figure 3a).

This observation also implies that the catalytic activity of Dronc is not strictly required for AiP and may offer an answer to another question that centers on the proteolytic target of Dronc for AiP. Although Dronc cleaves DrICE and Dcp-1 for induction of apoptosis, a specific cleavage target of Dronc for AiP has not been identified although there is evidence that Dronc has additional cleavage targets. ${ }^{81}$ The observation that Dronc $^{\mathrm{K} 78 \mathrm{RC} 318 \mathrm{~A}}$ can induce AiP may suggest that Dronc does not have a specific cleavage target for AiP. All Dronc needs for AiP is incorporation into the Dark apoptosome ${ }^{17}$ which is facilitated in the absence of K78 ubiquitylation. ${ }^{36}$ Therefore, the Dronc ${ }^{\text {K78RC318A }}$ mutant opens up exciting opportunities for future investigations not only regarding AiP but also other nonapoptotic functions of Dronc that are independent of effector caspase activation.

Regulating the targets: a role for adaptors and scaffolds directing AiP versus apoptotic death? It is clear that there is highly specific signaling that leads to $\mathrm{AiP}$, but another ongoing question is how are caspases directed to their nonapoptotic targets to promote AiP instead of apoptosis. As described above, Dronc interacts with the scaffolding protein Dark/Apaf-1 during the initiation of apoptosis. The apoptosome provides an environment that facilitates zymogen activation, and aggregation of caspase activity to cross the threshold to trigger apoptosis. ${ }^{82,83}$ When considering other non-apoptotic functions of Dronc, there are examples of accessory adaptors interacting with this scaffold to regulate and direct activity (Figure 3b). For example, in spermatid differentiation in Drosophila, active Dronc within the apoptosome is required for cellular remodeling that resolves the individual spermatids from a larger syncytium. ${ }^{84}$ Interestingly, during this non-apoptotic process the active apoptosome does not induce cell death. The apoptosome is activated and directed to the proper sub-cellular localization by an adaptor molecule, Tango7. ${ }^{85,86}$ Tango7 is required for Dronc to cleave its targets during this remodeling, with mutant alleles of Tango7 resulting in male sterility due to a failure of sperm individualization. $^{85}$

In contrast, the unconventional myosin Crinkled serves as an adaptor for caspase substrates during Dronc-dependent patterning, specifically guiding kinases such a GSK3 $\beta$ to active Dronc for cleavage and regulation of its activity. ${ }^{87}$ Both of these interactions were also found in mammals, with the Tango7 homolog PCID1 interacting with caspase-9, and the unconventional myosin MYO7A binding to and regulating a different initiator, caspase-8. ${ }^{86,87}$ Taken together these findings in Drosophila and mammals raise the possibility that some as of yet unidentified co-factors could physically interact with caspases to guide them to AiP targets preferentially over the cell death effectors, or bring AiP targets to active caspases while cell execution proceeds (Figure 3b).

Regulating the response: feedback loops modulate AiP activity. As detailed above, Dronc triggers AiP through JNK. While JNK is activated downstream of Dronc, JNK activation also leads to upregulation of pro-apoptotic hid, amplifying the initial apoptotic stimulus, caspase activity, and caspasedriven pathways like AiP (Figure 3c).$^{8,10,17,53,88}$ In the undead AiP model, the ROS-recruited hemocytes contribute to this JNK/Dronc feedback amplification (Figures $2 b$ and $3 c$ ). ${ }^{18}$ Blocking hemocytes in this model not only blocks JNK activity and AiP but also leads to reduced caspase activity in the undead cells, a feature not seen when blocking AiP at other downstream points. ${ }^{18}$ Adding yet another layer, there is some evidence that in certain contexts there is JNK-dependent non-autonomous positive amplification of the apoptotic pathway in surrounding cells (apoptosis-induced apoptosis), leading to increased caspase activity, and potentially further activating a wider AiP response. ${ }^{89,90}$ Conversely, EGFR signaling, another player activated downstream of JNK in $\mathrm{AiP},{ }^{17}$ negatively regulates Hid activity and reduces caspasedriven apoptosis in certain cell populations, reducing their susceptibility to cell death. ${ }^{91-93}$ This type of feedback could provide a mechanism to limit caspase-driven AiP preventing unregulated proliferation.

The AP-1 transcription factors c-Jun and c-Fos are important for many developmental control programs and, when specifically phosphorylated by JNK, can activate genes important for death, survival, cellular remodeling, or proliferation, depending on the context. ${ }^{57,94,95}$ In the context of regenerative proliferation, it was recently demonstrated that AP-1 can directly bind to a stress-responsive promoter element of the $w g$ gene which is only activated during regenerative responses. ${ }^{96}$ How JNK-activated AP-1 is directed to this element only under regenerative conditions is unknown, but other downstream pathways in AiP might contribute to regulation. For example Atg1, a serine/threonine kinase known for its role in autophagy, was recently identified as functioning downstream of JNK to promote AiP independently of autophagy. ${ }^{97}$ Therefore, Atg1 might act as a modulation factor directing the correct JNK-dependent cellular 
response to stress situations as in AiP. As new downstream factors like Atg1 are identified and characterized, we should expect to find more regulatory feedback opportunities finetuning AiP.

\section{The emerging clinical significance of caspase-driven AiP in cancer}

Given that the undead AiP model exploits a sustained induction of proliferation and results in abnormal, hyperplastic overgrowth, it has been proposed that this compensatory mechanism contributes to the aberrant proliferation seen in cancer. ${ }^{98}$ Indeed, a number of recent studies have been exploring the ways in which these physiological regenerative pathways may be deregulated in human disease and even hijacked in malignant transformation and growth.

Caspase-dependent tumor repopulation following cytotoxic therapies. Increased cell proliferation and rapid repopulation of tumors following cytotoxic therapy (either ionizing radiation or chemotherapies) has been a long known factor in poor treatment response in human cancers, but the exact mechanism behind this phenomenon had remained elusive. ${ }^{99,100}$ Following the description of caspase-3-driven $\mathrm{PGE}_{2}$-mediated proliferation in the context of tissue regeneration (Figure 2e), ${ }^{15}$ examples of caspase-dependent $\mathrm{PGE}_{2}$ production directly supporting tumor growth and repopulation following radiation therapy were found in mouse models and human cancer cell lines (Figure 4a). ${ }^{40,41}$ Since then, possible roles in repopulation for other AiP-associated factors including caspase-7, PKC $\delta$, Akt, p38, JNK1/2, SHH and HMGB1 have been identified (Figure 4a). ${ }^{42,43,101,102} \mathrm{~A}$ similar caspase/ $\mathrm{PGE}_{2}$ mechanisms of repopulation has also been found following cytotoxic chemotherapy, confirming this is not a radiation-specific response. ${ }^{103}$

AiP, chronic inflammation, and cancer risk. Separate from their direct role in tumor survival, apoptotic caspases may also contribute to tumor initiation, caspase-dependent inflammation, and sustained AiP in tumor initiation. Tumors have been described as analogous to wounds that do not heal, ${ }^{19}$ and tumor-promoting inflammation is an emerging hallmark of

Figure 4 AiP in cancer and treatment failure. Emerging clinical studies have found that high levels of activated caspase- 3 in tumors is associated with poor prognosis. Possible mechanisms by which caspase-mediated AiP could be contributing to tumorigenesis are modeled here. (a) Tumor repopulation following radiation or chemotherapy: cancer cells sensitive to the cytotoxic treatment initiate apoptosis and some cells trigger an AiP response through the production of $\mathrm{PGE}_{2}$ and other proliferative cytokines. Overall tumor bulk is initially reduced due to the apoptotic death, but the remaining cancer cells-including therapy-resistant cellsare stimulated via AiP to proliferate, repopulating the tumor. Over repeated cycles this could lead to extremely resistant tumors and eventual treatment failure. (b) Growth signals from dying tumor cells stimulate angiogenesis: caspase activation in dying tumor cells has been directly linked to VEGF-A production, a growth factor that promotes angiogenesis and neovascularization of the tumor. (c) Dying vascular endothelial cells also trigger AiP: caspase activation in the VE cells results in $\mathrm{PGE}_{2}$ production, which may stimulate further proliferation of the tumor cells cancer. ${ }^{104}$ Chronic inflammatory states, often characterized by repeated cycles of cell death and incomplete wound healing, are known to predispose to the development of certain cancers (Figure 1c). ${ }^{20}$ Inflammatory bowel diseases such as ulcerative colitis increase the risk of colorectal carcinomas; ${ }^{105}$ Marjolin's ulcers, a type of epidermoid carcinoma, can be found arising from chronically irritated skin or nonhealing scars; ${ }^{106}$ inflammation of the lungs in severe types of chronic obstructive pulmonary disease increases the risk of squamous cell lung cancer, beyond the risk from smoking exposure alone. ${ }^{107}$

a AiP Drives Tumor Repopulation Following Therapy

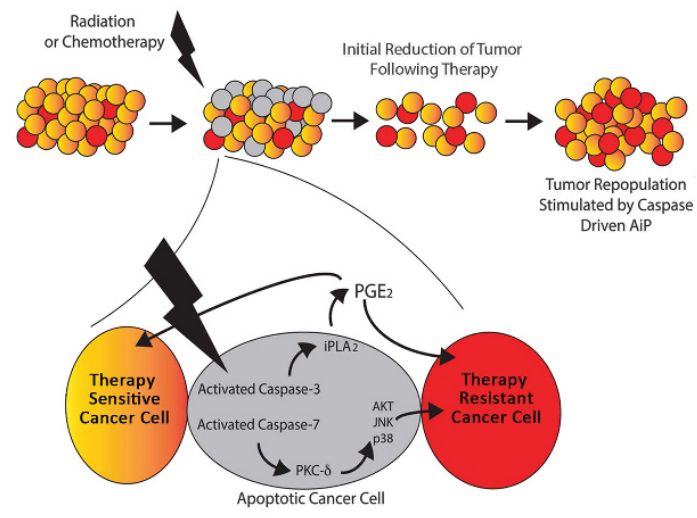

b AiP Promotes Angiogenesis Following Therapy

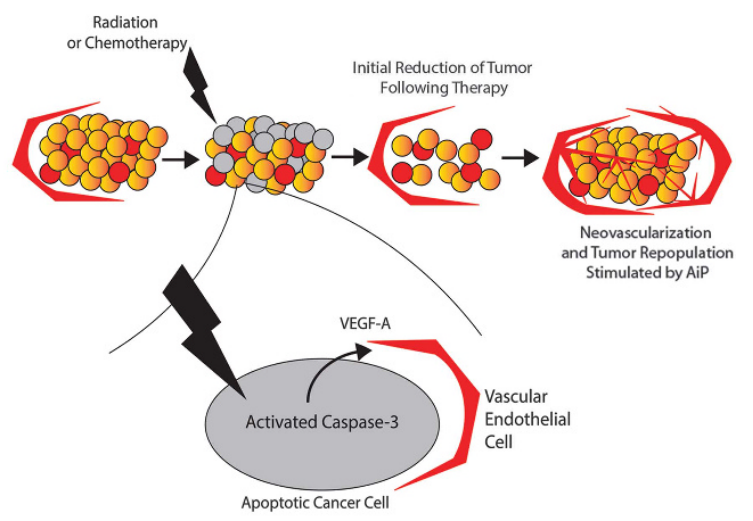

C Apoptotic Vessels Can Stimulate AiP in Tumors

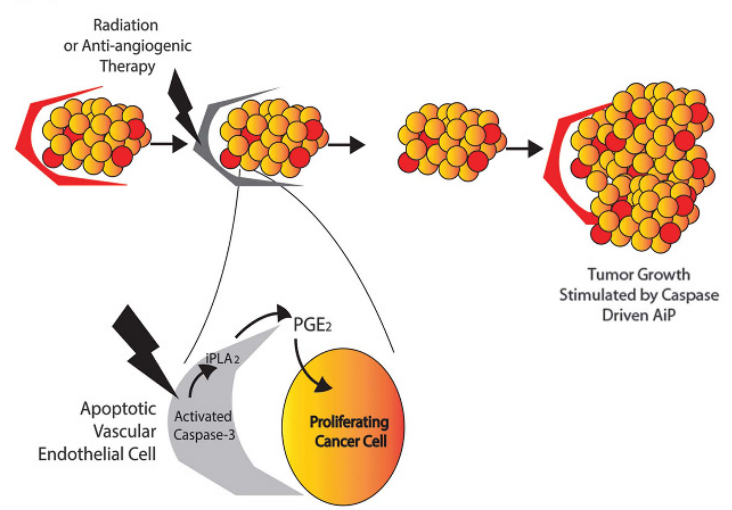


Just as there are opportunities to connect the dots between caspases and mechanisms of regeneration, recent studies have raised intriguing opportunities to connect AiP with inflammation-associated tumorigenesis. The initiator caspase-dependent model of AiP in Drosophila as described above has demonstrated direct connections between ROS, macrophage-like immune cells, JNK stress responses, EGFmediated signaling, hyperplasia and dysplasia. ${ }^{6-9,16-18,63}$ In models of human inflammatory pathologies, the connections are not characterized as rigorously, but conservation of key players is striking. For example, in a mouse model of ulcerative colitis in which colonic epithelial cells are exposed to oxidative stress, JNK signaling and non-apoptotic caspase activity were linked to each other through mutual feedback, to cell survival despite DNA damage, to increased proliferation, and to morphological changes in the epithelium consistent with early transformation. ${ }^{108}$ In another example, a chronicinjury model of liver carcinogenesis in mice showed compensatory proliferation and subsequent tumor formation is mediated by an EGFR-dependent activation of liver macrophages following hepatocyte cell death. ${ }^{109}$ Downregulation of apoptotic caspases in the parenchyma is sufficient to prevent the development of these tumors. ${ }^{110}$

AiP and vasculogenesis in the tumor microenvironment. Thus far, we have focused on the effects of AiP triggered by caspase-activated cells of one type acting on neighboring cells of the same type, with or without an immune intermediate. However, caspase-dependent AiP can extend to other cell types in the microenvironment. While cytotoxic radiotherapy targeting tumor cells can paradoxically drive AiP-mediated tumor repopulation as described above (Figure 4a), it can also trigger neovascularization and angiogenesis via mitogens acting on vascular endothelial (VE) cells. This post-irradiation angiogenesis (PIA) is thought to contribute to radiotherapy failure in certain cancers, and new evidence suggests this could be partly due to a form of caspase-3-dependent AiP acting on VE cells (Figure 4b). ${ }^{44,111}$ Blocking caspase-3 in irradiated glioma cells attenuates new vessel formation, which in turn suppresses overall tumorigenicity. ${ }^{111}$ Caspase-3-dependent production of VEGF-A by these tumor cells appears to be one of the major factors contributing to PIA, but several caspase-3-activated signaling pathways may contribute to a pro-angiogenic microenvironment for VE cell proliferation. $^{44}$

However, simply blocking angiogenesis is not a panacea. ${ }^{112}$ VE cells activate caspase- 3 following cytotoxic treatments triggering their own production of the diffusible AiP factor $\mathrm{PGE}_{2}$, enhancing tumor growth which can lead to therapy resistance (Figure 4c). ${ }^{113}$ In addition, independent of formal angiogenesis, some especially aggressive tumor types can generate a blood and nutrient supply via a process known as vasculogenic mimicry (VM). ${ }^{114}$ VM appears to also involve a non-apoptotic function of caspases, as caspase-3 activity contributes to the proliferation of vessel-like channels formed from highly aggressive cancer cells in certain human melanomas. ${ }^{38}$ Very little is known about the precise mechanisms of VM, but this may represent more of a caspasedependent invasion and metastasis phenotype than true AiP.
Ongoing work in model organisms, is currently investigating the relationship between caspases, extracellular matrix remodeling, and metastatic potential. ${ }^{115}$

Clinical implications for prognosis and improved treatments. Several independent patient cohort studies are now confirming the clinical relevance of caspase-dependent repopulation and other non-apoptotic functions of caspases in these tumors (Figure 4a), finding significant associations between poor prognosis and elevated caspase-3 expression and activity. In one study, increased active caspase-3 in biopsy samples before initiating treatment correlated with significantly shorter overall survival time in gastric, cervical, colorectal, and ovarian tumors. ${ }^{116}$ In another study, elevated circulating serum levels of caspase activity correlated with shorter time to progression despite chemotherapy in head and neck cancers. ${ }^{117}$ In a third study, activated caspase-3 and increased HMGB1 expression were found in colorectal cancers and were correlated with poor prognosis, independent of their function in metastasis. ${ }^{43}$

As the details of caspase-dependent AiP and their vital significance in humans are clarified, the logical next questions center on employing this knowledge to refine cancer therapy or even prevent it before it starts. A few experiments have started to address these questions and have shown promise in leveraging our understanding of AiP to improve cancer treatment strategies. For example, knowing that there is redundancy in AiP signaling, targeting one AiP pathway is likely not enough, and subsequent cycles of AiP might expedite and amplify drug-resistance. One study found modest success in improving colorectal cancer cell killing in vitro by combining a pro-apoptotic chemotherapeutic with a cocktail of inhibitors targeting AKT, STAT3 and ERK1/2, three likely AiP-associated survival and proliferation pathways. ${ }^{118}$ Two other studies have successfully employed in vivo administration of celecoxib, an inhibitor of the enzyme cyclooxygenase-2 (COX2) that synthesizes $\mathrm{PGE}_{2}$ downstream of $\mathrm{iPLA}_{2}$, as adjuvant therapy following standard cytotoxic treatments to prevent tumor progression and suppress tumor repopulation in a mouse model of melanoma and a xenograft model of bladder cancer, respectively. ${ }^{103,119}$

Yet, other questions remain wide open. Are there key regulatory points in these caspase-dependent pathways that can be targeted, to distinguish between the various pleiotropic effects, enhancing the desired anti-tumor functions while suppressing the undesired pro-tumor functions? What upstream factors or environmental conditions are driving cancer cells to have such high caspase levels, even before the stress of treatment, priming them for a robust $\mathrm{AiP}$ response? Can this knowledge of AiP be harnessed for the field of regenerative medicine in a way that does not increase future risk of malignancy?

\section{Conclusion}

Caspases are critical not only for apoptotic cell death but can also stimulate proliferation in response to either death or non-lethal stresses. Caspase-dependent AiP is not a single pathway, but an evolutionarily conserved process which provides mechanisms for healing and adaptation in the face 
of an injurious world. Despite the incredible progress made over the past decade, there are likely more mechanisms of AiP that have yet to be uncovered, more upstream regulators influencing life versus death functions of caspases and more downstream caspase targets to effect those functions. Continued work probing AiP in genetically tractable model organisms will provide clues for which players and pathways may be at work in human diseases, while clinical investigations will guide the search for non-apoptotic caspase involvement in new contexts, potentially informing novel therapies and improving patient outcomes.

\section{Conflict of Interest}

The authors declare no conflict of interest.

Acknowledgements. We apologize to our colleagues whose work was not cited due to space restrictions. We thank Yun Fan, Alla Amcheslavsky, Elif Kamber Kaya and Neha Diwanji for stimulating discussions in the course of this work. This work was supported by the National Institute of General Medical Sciences (NIGMS) under award numbers R01GM107789 and R35GM118330.

1. Haynie JL, Bryant PJ. The effects of X-rays on the proliferation dynamics of cells in the imaginal wing disc of Drosophila melanogaster. Dev Genes Evol 1977; 183: 85-100.

2. James AA, Bryant PJ. A quantitative study of cell death and mitotic inhibition in gamma-irradiated imaginal wing discs of Drosophila melanogaster. Radiat Res 1981; 87: 552-564.

3. Milan M, Campuzano S, Garcia-Bellido A. Developmental parameters of cell death in the wing disc of Drosophila. Proc Natl Acad Sci USA 1997; 94: 5691-5696.

4. Hwang JS, Kobayashi C, Agata K, Ikeo K, Gojobori T. Detection of apoptosis during planarian regeneration by the expression of apoptosis-related genes and TUNEL assay. Gene 2004; 333: 15-25.

5. Vlaskalin T, Wong CJ, Tsilfidis C. Growth and apoptosis during larval forelimb development and adult forelimb regeneration in the newt (Notophthalmus viridescens). Dev Genes Evol 2004; 214: 423-431.

6. Huh JR, Guo M, Hay BA. Compensatory proliferation induced by cell death in the Drosophila wing disc requires activity of the apical cell death caspase Dronc in a nonapoptotic role. Curr Biol 2004; 14: 1262-1266.

7. Perez-Garijo A, Martin FA, Morata G. Caspase inhibition during apoptosis causes abnormal signalling and developmental aberrations in Drosophila. Development 2004; 131 $5591-5598$.

8. Ryoo HD, Gorenc T, Steller H. Apoptotic cells can induce compensatory cell proliferation through the JNK and the Wingless signaling pathways. Dev Cell 2004; 7: 491-501.

9. Kondo S, Senoo-Matsuda N, Hiromi Y, Miura M. DRONC coordinates cell death and compensatory proliferation. Mol Cell Biol 2006; 26: 7258-7268.

10. Wells BS, Yoshida E, Johnston LA. Compensatory proliferation in Drosophila imaginal discs requires Dronc-dependent p53 activity. Curr Biol 2006; 16: 1606-1615.

11. Mollereau B, Perez-Garijo A, Bergmann A, Miura M, Gerlitz O, Ryoo HD et al. Compensatory proliferation and apoptosis-induced proliferation: a need for clarification. Cell Death Differ 2012; 20: 181.

12. Tseng AS, Adams DS, Qu D, Koustubhan P, Levin M. Apoptosis is required during early stages of tail regeneration in Xenopus laevis. Dev Biol 2007; 301: 62-69.

13. Fan $Y$, Bergmann A. Distinct mechanisms of apoptosis-induced compensatory proliferation in proliferating and differentiating tissues in the Drosophila eye. Dev Cell 2008; 14: 399-410.

14. Chera S, Ghila L, Dobretz K, Wenger Y, Bauer C, Buzgariu W et al. Apoptotic cells provide an unexpected source of Wnt3 signaling to drive hydra head regeneration. Dev Cell 2009; 17: $279-289$.

15. Li F, Huang Q, Chen J, Peng Y, Roop DR, Bedford JS et al. Apoptotic cells activate the 'phoenix rising' pathway to promote wound healing and tissue regeneration. Sci Signal 2010; 3: ra13.

16. Perez-Garijo A, Martin FA, Struhl G, Morata G. Dpp signaling and the induction of neoplastic tumors by caspase-inhibited apoptotic cells in Drosophila. Proc Natl Acad Sci USA 2005; 102: 17664-17669.

17. Fan Y, Wang S, Hernandez J, Yenigun VB, Hertlein G, Fogarty CE et al. Genetic models of apoptosis-induced proliferation decipher activation of JNK and identify a requirement of EGFR signaling for tissue regenerative responses in Drosophila. PLoS Genet 2014; 10: e1004131.

18. Fogarty CE, Diwanji N, Lindblad JL, Tare M, Amcheslavsky A, Makhijani K et al. Extracellular reactive oxygen species drive apoptosis-induced proliferation via Drosophila macrophages. Curr Biol 2016; 26: 575-584.
19. Dvorak HF. Tumors: wounds that do not heal. Similarities between tumor stroma generation and wound healing. N Engl J Med 1986; 315: 1650-1659.

20. Karin $\mathrm{M}, \mathrm{Clevers} \mathrm{H}$. Reparative inflammation takes charge of tissue regeneration. Nature 2016; 529: 307-315.

21. Shalini S, Dorstyn L, Dawar S, Kumar S. Old, new and emerging functions of caspases. Cell Death Differ 2015; 22: 526-539.

22. Xu D, Woodfield SE, Lee TV, Fan Y, Antonio C, Bergmann A. Genetic control of programmed cell death (apoptosis) in Drosophila. Fly (Austin) 2009; 3: 78-90.

23. Conradt B. Genetic control of programmed cell death during animal development. Annu Rev Genet 2009; 43: 493-523.

24. Fuchs $\mathrm{Y}$, Steller H. Programmed cell death in animal development and disease. Cell 2011; 147: 742-758.

25. Czabotar PE, Lessene G, Strasser A, Adams JM. Control of apoptosis by the BCL-2 protein family: implications for physiology and therapy. Nat Rev Mol Cell Biol 2014; 15: 49-63.

26. Goyal L, McCall K, Agapite J, Hartwieg E, Steller H. Induction of apoptosis by Drosophila reaper, hid and grim through inhibition of IAP function. EMBO J 2000; 19: 589-597.

27. Lisi S, Mazzon I, White K. Diverse domains of THREAD/DIAP1 are required to inhibit apoptosis induced by REAPER and HID in Drosophila. Genetics 2000; 154: $669-678$.

28. White K, Grether ME, Abrams JM, Young L, Farrell K, Steller H. Genetic control of programmed cell death in Drosophila. Science 1994; 264: 677-683.

29. Grether ME, Abrams JM, Agapite J, White K, Steller $\mathrm{H}$. The head involution defective gene of Drosophila melanogaster functions in programmed cell death. Genes Dev 1995; 9: 1694-1708.

30. Chen P, Nordstrom W, Gish B, Abrams JM. grim, a novel cell death gene in Drosophila. Genes Dev 1996; 10: 1773-1782.

31. Bergmann A. The role of ubiquitylation for the control of cell death in Drosophila. Cell Death Differ 2010; 17: 61-67.

32. Shapiro PJ, Hsu HH, Jung H, Robbins ES, Ryoo HD. Regulation of the Drosophila apoptosome through feedback inhibition. Nat Cell Biol 2008; 10: 1440-1446.

33. Wilson R, Goyal L, Ditzel M, Zachariou A, Baker DA, Agapite J et al. The DIAP1 RING finger mediates ubiquitination of Dronc and is indispensable for regulating apoptosis. Nat Cell Biol 2002; 4: 445-450.

34. Chai J, Yan N, Huh JR, Wu JW, Li W, Hay BA et al. Molecular mechanism of Reaper-GrimHid-mediated suppression of DIAP1-dependent Dronc ubiquitination. Nat Struct Biol 2003; 10: 892-898.

35. Lee TV, Fan Y, Wang S, Srivastava M, Broemer M, Meier P et al. Drosophila IAP1mediated ubiquitylation controls activation of the initiator caspase DRONC independent of protein degradation. PLoS Genet 2011; 7: e1002261.

36. Kamber Kaya HE, Ditzel M, Meier P, Bergmann A. An inhibitory mono-ubiquitylation of the Drosophila initiator caspase Dronc functions in both apoptotic and non-apoptotic pathways. PLoS Genet 2017; 13: e1006438.

37. Florentin A, Arama E. Caspase levels and execution efficiencies determine the apoptotic potential of the cell. J Cell Biol 2012; 196: 513-527.

38. Liu YR, Sun B, Zhao XL, Gu Q, Liu ZY, Dong XY et al. Basal caspase-3 activity promotes migration, invasion, and vasculogenic mimicry formation of melanoma cells. Melanoma Res 2013; 23: 243-253

39. Dabrowska C, Li M, Fan Y. Apoptotic caspases in promoting cancer: implications from their roles in development and tissue homeostasis. Adv Exp Med Biol 2016; 930: 89-112.

40. Huang Q, Li F, Liu X, Li W, Shi W, Liu FF et al. Caspase 3-mediated stimulation of tumor cell repopulation during cancer radiotherapy. Nat Med 2011; 17: 860-866.

41. Donato AL, Huang Q, Liu X, Li F, Zimmerman MA, Li CY. Caspase 3 promotes surviving melanoma tumor cell growth after cytotoxic therapy. J Invest Dermatol 2014; 134 : 1686-1692.

42. Cheng J, Tian L, Ma J, Gong Y, Zhang Z, Chen Z et al. Dying tumor cells stimulate proliferation of living tumor cells via caspase-dependent protein kinase Cdelta activation in pancreatic ductal adenocarcinoma. Mol Oncol 2015; 9: 105-114.

43. Zhang Z, Wang M, Zhou L, Feng X, Cheng J, Yu Y et al. Increased HMGB1 and cleaved caspase-3 stimulate the proliferation of tumor cells and are correlated with the poor prognosis in colorectal cancer. J Exp Clin Cancer Res 2015; 34: 51.

44. Feng $X, Y u$ Y, He S, Cheng J, Gong Y, Zhang $Z$ et al. Dying glioma cells establish a proangiogenic microenvironment through a caspase 3 dependent mechanism. Cancer Lett 2016; 385: 12-20.

45. Kumar S. Caspase function in programmed cell death. Cell Death Differ 2007; 14: 32-43.

46. Fan Y, Bergmann A. Apoptosis-induced compensatory proliferation. The cell is dead. Long live the Cell!. Trends Cell Biol 2008; 18: 467-473.

47. Smith-Bolton R. Drosophila imaginal discs as a model of epithelial wound repair and regeneration. Adv Wound Care (New Rochelle) 2016; 5: 251-261.

48. Clem RJ, Fechheimer M, Miller LK. Prevention of apoptosis by a baculovirus gene during infection of insect cells. Science 1991; 254: 1388-1390.

49. Hay BA, Wolff T, Rubin GM. Expression of baculovirus P35 prevents cell death in Drosophila. Development 1994; 120: 2121-2129.

50. Martin FA, Perez-Garijo A, Morata G. Apoptosis in Drosophila: compensatory proliferation and undead cells. Int J Dev Biol 2009; 53: 1341-1347.

51. Perez-Garijo A, Shlevkov E, Morata G. The role of Dpp and $\mathrm{Wg}$ in compensatory proliferation and in the formation of hyperplastic overgrowths caused by apoptotic cells in the Drosophila wing disc. Development 2009; 136: 1169-1177. 
52. Mollereau B, Perez-Garijo A, Bergmann A, Miura M, Gerlitz O, Ryoo HD et al. Compensatory proliferation and apoptosis-induced proliferation: a need for clarification. Cell Death Differ 2013; 20: 181

53. Shlevkov E, Morata G. A dp53/JNK-dependant feedback amplification loop is essential for the apoptotic response to stress in Drosophila. Cell Death Differ 2012; 19: 451-460.

54. Santabarbara-Ruiz P, Lopez-Santillan M, Martinez-Rodriguez I, Binagui-Casas A, Perez L, Milan $\mathrm{M}$ et al. ROS-Induced JNK and p38 signaling is required for unpaired cytokine activation during Drosophila regeneration. PLoS Genet 2015; 11: e1005595.

55. Xu D, Li Y, Arcaro M, Lackey M, Bergmann A. The CARD-carrying caspase Dronc is essential for most, but not all, developmental cell death in Drosophila. Development 2005; 132: $2125-2134$.

56. Igaki T. Correcting developmental errors by apoptosis: lessons from Drosophila JNK signaling. Apoptosis 2009; 14: 1021-1028.

57. Rios-Barrera LD, Riesgo-Escovar JR. Regulating cell morphogenesis: the Drosophila Jun N-terminal kinase pathway. Genesis 2013; 51: 147-162.

58. Clavier A, Rincheval-Arnold A, Baillet A, Mignotte B, Guenal I. Two different specific JNK activators are required to trigger apoptosis or compensatory proliferation in response to Rbf1 in Drosophila. Cell Cycle 2016; 15: 283-294.

59. Scott EW, Simon MC, Anastasi J, Singh H. Requirement of transcription factor PU.1 in the development of multiple hematopoietic lineages. Science 1994; 265: 1573-1577.

60. Martin P, D'Souza D, Martin J, Grose R, Cooper L, Maki R et al. Wound healing in the PU.1 null mouse-tissue repair is not dependent on inflammatory cells. Curr Biol 2003; 13: $1122-1128$.

61. Niethammer P, Grabher C, Look AT, Mitchison TJ. A tissue-scale gradient of hydrogen peroxide mediates rapid wound detection in zebrafish. Nature 2009; 459: 996-999.

62. Razzell W, Evans IR, Martin P, Wood W. Calcium flashes orchestrate the wound inflammatory response through DUOX activation and hydrogen peroxide release. Curr Biol 2013; 23: 424-429.

63. Diwanii N, Bergmann A. The beneficial role of extracellular reactive oxygen species in apoptosis-induced compensatory proliferation. Fly (Austin) 2016; 11: 1-7.

64. Smith-Bolton RK, Worley MI, Kanda H, Hariharan IK. Regenerative growth in Drosophila imaginal discs is regulated by Wingless and Myc. Dev Cell 2009; 16: 797-809.

65. Bergantinos C, Corominas M, Serras F. Cell death-induced regeneration in wing imaginal discs requires JNK signalling. Development 2010; 137: 1169-1179.

66. Herrera SC, Martin R, Morata G. Tissue homeostasis in the wing disc of Drosophila melanogaster: immediate response to massive damage during development. PLoS Genet 2013; 9: e1003446.

67. Kashio S, Obata F, Zhang L, Katsuyama T, Chihara T, Miura M. Tissue nonautonomous effects of fat body methionine metabolism on imaginal disc repair in Drosophila. Proc Natl Acad Sci USA 2016; 113: 1835-1840.

68. Meserve JH, Duronio RJ. Scalloped and Yorkie are required for cell cycle re-entry of quiescent cells after tissue damage. Development 2015; 142: 2740-2751.

69. Atsumi G, Tajima M, Hadano A, Nakatani Y, Murakami M, Kudo I. Fas-induced arachidonic acid release is mediated by $\mathrm{Ca} 2+-$ independent phospholipase $\mathrm{A} 2$ but not cytosolic phospholipase A2, which undergoes proteolytic inactivation. J Biol Chem 1998; 273: 13870-13877.

70. Lauber K, Bohn E, Krober SM, Xiao YJ, Blumenthal SG, Lindemann RK et al. Apoptotic cells induce migration of phagocytes via caspase-3-mediated release of a lipid attraction signal. Cell 2003; 113: 717-730.

71. Hagedorn EJ, Durand EM, Fast EM, Zon LI. Getting more for your marrow: boosting hematopoietic stem cell numbers with PGE2. Exp Cell Res 2014; 329: 220-226.

72. North TE, Goessling W, Walkley CR, Lengerke C, Kopani KR, Lord AM et al. Prostaglandin E2 regulates vertebrate haematopoietic stem cell homeostasis. Nature 2007; 447: 1007-1011.

73. Zhang Y, Desai A, Yang SY, Bae KB, Antczak MI, Fink SP et al. TISSUE REGENERATION. Inhibition of the prostaglandin-degrading enzyme 15-PGDH potentiates tissue regeneration. Science 2015; 348: aaa2340.

74. Schieber M, Chandel NS. ROS function in redox signaling and oxidative stress. Curr Biol 2014; 24: R453-R462.

75. Vriz S, Reiter S, Galliot B. Cell death: a program to regenerate. Curr Top Dev Biol 2014; 108: 121-151.

76. Nishina T, Komazawa-Sakon S, Yanaka S, Piao X, Zheng DM, Piao JH et al. Interleukin-11 links oxidative stress and compensatory proliferation. Sci Signal 2012; 5: ra5.

77. Gauron C, Rampon C, Bouzaffour M, Ipendey E, Teillon J, Volovitch M et al. Sustained production of ROS triggers compensatory proliferation and is required for regeneration to proceed. Scientific reports 2013; 3: 2084.

78. Love NR, Chen Y, Ishibashi S, Kritsiligkou P, Lea R, Koh Y et al. Amputation-induced reactive oxygen species are required for successful Xenopus tadpole tail regeneration. Nat Cell Biol 2013; 15: 222-228.

79. Muro I, Monser K, Clem RJ. Mechanism of Dronc activation in Drosophila cells. J Cell Sci 2004; 117: 5035-5041.

80. Koerver L, Melzer J, Roca EA, Teichert D, Glatter T, Arama E et al. The de-ubiquitylating enzyme DUBA is essential for spermatogenesis in Drosophila. Cell Death Differ 2016; 23: 2019-2030.

81. Fan Y, Bergmann A. The cleaved-Caspase-3 antibody is a marker of Caspase-9-like DRONC activity in Drosophila. Cell Death Differ 2010; 17: 534-539.

82. Salvesen GS, Renatus M. Apoptosome: the seven-spoked death machine. Dev Cell 2002; 2: $256-257$.
83. Shi Y. Apoptosome: the cellular engine for the activation of caspase-9. Structure 2002; 10: 285-288.

84. Arama $\mathrm{E}$, Agapite J, Steller $\mathrm{H}$. Caspase activity and a specific cytochrome $\mathrm{C}$ are required for sperm differentiation in Drosophila. Dev Cell 2003; 4: 687-697.

85. D'Brot A, Chen P, Vaishnav M, Yuan S, Akey CW, Abrams JM. Tango7 directs cellular remodeling by the Drosophila apoptosome. Genes Dev 2013; 27: 1650-1655.

86. Chew SK, Chen P, Link N, Galindo KA, Pogue K, Abrams JM. Genome-wide silencing in Drosophila captures conserved apoptotic effectors. Nature 2009; 460: 123-127.

87. Orme MH, Liccardi G, Moderau N, Feltham R, Wicky-John S, Tenev T et al. The unconventional myosin CRINKLED and its mammalian orthologue MYO7A regulate caspases in their signalling roles. Nat Commun 2016; 7: 10972.

88. Moreno E, Yan M, Basler K. Evolution of TNF signaling mechanisms: JNK-dependent apoptosis triggered by Eiger, the Drosophila homolog of the TNF superfamily. Curr Biol 2002; 12: 1263-1268.

89. Suissa Y, Ziv O, Dinur T, Arama E, Gerlitz O. The NAB-Brk signal bifurcates at JNK to independently induce apoptosis and compensatory proliferation. J Biol Chem 2011; 286: 15556-15564.

90. Perez-Garijo A, Fuchs $Y$, Steller H. Apoptotic cells can induce non-autonomous apoptosis through the TNF pathway. Elife 2013; 2: e01004.

91. Bergmann A, Agapite J, McCall K, Steller H. The Drosophila gene hid is a direct molecular target of Ras-dependent survival signaling. Cell 1998; 95: 331-341.

92. Kurada $\mathrm{P}$, White K. Ras promotes cell survival in Drosophila by downregulating hid expression. Cell 1998; 95: 319-329.

93. Fan Y, Bergmann A. Multiple mechanisms modulate distinct cellular susceptibilities toward apoptosis in the developing Drosophila eye. Dev Cell 2014; 30: 48-60.

94. Kockel L, Homsy JG, Bohmann D. Drosophila AP-1: lessons from an invertebrate. Oncogene 2001; 20: 2347-2364.

95. Ramet M, Lanot R, Zachary D, Manfruelli P. JNK signaling pathway is required for efficient wound healing in Drosophila. Dev Biol 2002; 241: 145-156

96. Harris RE, Setiawan L, Saul J, Hariharan IK. Localized epigenetic silencing of a damageactivated WNT enhancer limits regeneration in mature Drosophila imaginal discs. Elife 2016; 5: e11588.

97. Li M, Lindblad JL, Perez E, Bergmann A, Fan Y. Autophagy-independent function of Atg1 for apoptosis-induced compensatory proliferation. BMC Biol 2016; $14: 70$.

98. Ryoo HD, Bergmann A. The role of apoptosis-induced proliferation for regeneration and cancer. Cold Spring Harb Perspect Biol 2012; 4: a008797.

99. Tubiana M. The kinetics of tumour cell proliferation and radiotherapy. Br J Radiol 1971; 44 325-347.

100. Tubiana M. Repopulation in human tumors. A biological background for fractionation in radiotherapy. Acta Oncol 1988; 27: 83-88.

101. Ma J, Tian L, Cheng J, Chen Z, Xu B, Wang L et al. Sonic hedgehog signaling pathway supports cancer cell growth during cancer radiotherapy. PLoS One 2013; 8: e65032.

102. Ma J, Cheng J, Gong Y, Tian L, Huang Q. Wnt signaling downregulated after sonic hedgehog activation negatively associates with tumor repopulation. Dis Model Mech 2015; 8: 385-391.

103. Kurtova AV, Xiao J, Mo Q, Pazhanisamy S, Krasnow R, Lerner SP et al. Blocking PGE2-induced tumour repopulation abrogates bladder cancer chemoresistance. Nature 2015; 517: 209-213.

104. Hanahan D, Weinberg RA. Hallmarks of cancer: the next generation. Cell 2011; 144 646-674

105. Romano M, DE Francesco F, Zarantonello L, Ruffolo C, Ferraro GA, Zanus G et al. From inflammation to cancer in inflammatory bowel disease: molecular perspectives. Anticancer Res 2016; 36: 1447-1460.

106. Shen $R$, Zhang J, Zhang $F, D u ~ Y$, Liang $W, X u L$ et al. Clinical characteristics and therapeutic analysis of 51 patients with Marjolin's ulcers. Exp Ther Med 2015; 10 1364-1374.

107. Bozinovski S, Vlahos R, Anthony D, McQualter J, Anderson G, Irving L et al. COPD and squamous cell lung cancer: aberrant inflammation and immunity is the common link. $\mathrm{Br} J$ Pharmacol 2016; 173: 635-648.

108. Poehlmann A, Reissig K, Just A, Walluscheck D, Hartig R, Schinlauer A et al. Non-apoptotic function of caspases in a cellular model of hydrogen peroxide-associated colitis. J Cell Mol Med 2013; 17: 901-913.

109. Lanaya H, Natarajan A, Komposch K, Li L, Amberg N, Chen L et al. EGFR has a tumourpromoting role in liver macrophages during hepatocellular carcinoma formation. Nat $\mathrm{Cell}$ Biol 2014; 16: 972-981 971-977.

110. Wree A, Johnson CD, Font-Burgada J, Eguchi A, Povero D, Karin M et al. Hepatocytespecific Bid depletion reduces tumor development by suppressing inflammation-related compensatory proliferation. Cell Death Differ 2015; 22: 1985-1994.

111. Feng X, Tian L, Zhang Z, Yu Y, Cheng J, Gong Y et al. Caspase 3 in dying tumor cells mediates post-irradiation angiogenesis. Oncotarget 2015; 6: 32353-32367.

112. Sitohy B, Nagy JA, Dvorak HF. Anti-VEGFNEGFR therapy for cancer: reassessing the target. Cancer Res 2012; 72: 1909-1914.

113. Mao $P, S$ mith $L$, Xie W, Wang $M$. Dying endothelial cells stimulate proliferation of malignant glioma cells via a caspase 3-mediated pathway. Oncol Lett 2013; 5: 1615-1620.

114. Maniotis AJ, Folberg R, Hess A, Seftor EA, Gardner LM, Pe'er J et al. Vascular channe formation by human melanoma cells in vivo and in vitro: vasculogenic mimicry. Am J Pathol 1999; 155: 739-752. 
115. Rudrapatna VA, Bangi E, Cagan RL. Caspase signalling in the absence of apoptosis drives Jnk-dependent invasion. EMBO Rep 2013; 14: 172-177.

116. Hu Q, Peng J, Liu W, He X, Cui L, Chen X et al. Elevated cleaved caspase- 3 is associated with shortened overall survival in several cancer types. Int J Clin Exp Pathol 2014; 7: 5057-5070.

117. John K, Rosner I, Keilholz U, Gauler T, Bantel H, Grunwald V. Baseline caspase activity predicts progression free survival of temsirolimus-treated head neck cancer patients. Eur $J$ Cancer 2015; 51: 1596-1602.

118. Bordonaro M, Drago E, Atamna W, Lazarova DL. Comprehensive suppression of all apoptosis-induced proliferation pathways as a proposed approach to colorectal cancer prevention and therapy. PLoS One 2014; 9: e115068.

119. Zelenay S, van der Veen AG, Bottcher JP, Snelgrove KJ, Rogers N, Acton SE et al. Cyclooxygenase-dependent tumor growth through evasion of immunity. Cell 2015; 162 1257-1270. (c) $(i) \&$ This work is licensed under a Creative Commons Attribution-NonCommercial-NoDerivs 4.0 International License. The images or other third party material in this article are included in the article's Creative Commons license, unless indicated otherwise in the credit line; if the material is not included under the Creative Commons license, users will need to obtain permission from the license holder to reproduce the material. To view a copy of this license, visit http://creativecommons.org/licenses/by-nc-nd/4.0/

(C) The Author(s) 2017 